\title{
Autonomy and Just Health
}

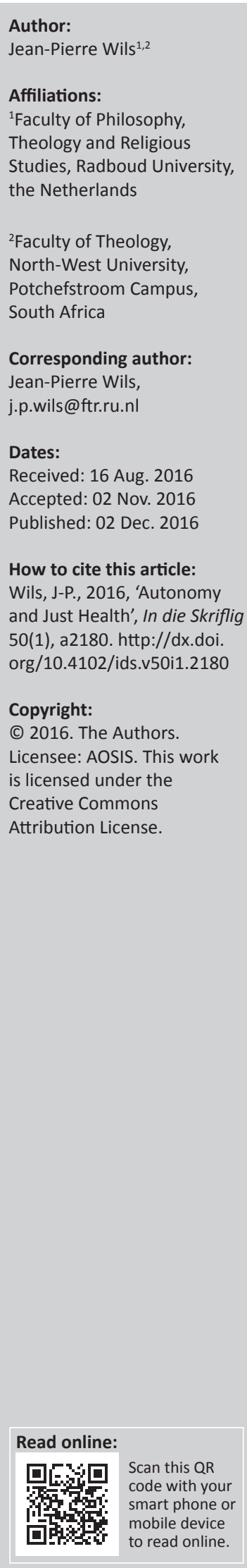

In the last quarter of the 20th century medical ethics underwent a kind of renaissance: developments in biotechnology, in pharmacy, but, overall, increased possibilities in lifestyles and life-extension due to advanced technological approaches captured our attention and led to a rehabilitation of ethics in general and medical ethics in particular. Initially these ethics operated with relatively simple principles. These principles, as they have been formulated by Tom L. Beauchamp and James F. Childress (1994), sound like a mantra to our ears: 'Autonomy', 'Nonmaleficence', 'Beneficence', and 'Justice'. Compared to the other three, the last named principle, 'Justice', has led and, until the present day, continues to lead a shadowy existence. The question of what 'just healthcare' means, and especially what 'just health' is, is hardly ever raised. In addition to this, the social characteristics of 'health' have been forgotten in a reprehensible way. A future medical ethics must deal with two key challenges. First, what is the good of health and how is it constituted? Second, what can 'just health' mean if we view it against the background of the social causes of health and disease.

People conceive and create goods, which they then distribute among themselves. Her, the conception and creation precede and control the distribution. Goods don't just appear in the hands of distributive agents who do with them as they like or give them out in accordance with some general principle. Rather, goods with their meaning - because of their meanings - are the crucial medium of social relations; they come into people's minds before they come into their hands; distributions are patterned in accordance with shared conceptions of what the goods are and what they are for. Distributive agents are constrained by the goods they hold; one might almost say that goods distribute themselves among peoples. (Michael Walzer 1983:6ff.)

\section{'Health' as a 'political issue'}

Medical ethics have the tendency to isolate moral conflicts from their social contexts. For this reason, questions of justice play only a minor role there. From the tradition of the medical ethics, mainly the principles of 'nonmaleficence' and 'beneficence' are known to us. These principles originate from a time in which, due to the lack of effective therapeutic abilities of action, the medical practice had the main task to prevent evil from the patient. Since the 1960s, it was 'patience autonomy' that became increasingly important. There will be a detailed reference to it in the course of this article. However justice in medical affairs has never got and enjoyed the prominence, which in particular the latter, viz. the patience autonomy, could achieve. Those questions of justice, which are of immediate and direct relevance, will be illustrated by the European examples of Greece and Spain. Those who neglect questions of justice have no sight for the grave health relevant consequences of an austerity policy as it was and still is practiced in succession of the great financial crisis in many countries to consolidate their national budgets.

In Greek medical centres, emergency ambulances have been closed for several days a week since 2012 because of money shortage. These ambulances treated patients free of charge and thus had to cope with waves of unemployed and no longer medically insured people. According to different shocking reports in German newspapers of January 2012, the ambulance of the PapageorgiouHospital in Thessaloniki had to treat up to 1500 patients per day. Now, just as a comparison: The ambulance of the largest medical centre in Europe, the Charité in Berlin, gets 580 patients done per day - at most! In the emergency ambulance Rechts-der-Isar in Munich about 70 people are looked after per day. In Greece, security agencies protected doctors against desperate patients and patients against other patients. Before operations people were sometimes asked to buy the needed threads themselves at the chemists, because the hospital was no longer provided with the needed basic utensils. Even cancer medicaments had to be financed in advance by the patients for the time being. As many were unable to do so, they died ahead of time. Repeatedly, the sentence is heard from the medical personnel: 'It is like a war'. German media reported that, at that time in Spain, 21 emergency ambulances had to be closed in rural areas because of economy measures. The nearest hospital for the population of such areas was about $150 \mathrm{~km}$ away. The consequences 
of these measures need no comments. David Stuckler and Sanjay Basu (2013) have very impressively described the disastrous consequences of those budgetary refurbishments in their book The Body Economic: Why Austerity Kills. And indeed, it is nothing less than the question of 'Politics of Life and Death'. Questions of justice in the sphere of health care always and inevitably have to do with a 'Distribution of Life and Death'. Health is in any case a politicum [political issue].

\section{Solidarity as a virtue and institutional 'form of control'}

What has happened? Meanwhile we lack a feeling 'what we owe each other' (Scanlon 1999). This phrasing implies no highly moral appeal immediately addressed to the individual conscience. There is no doubt that the individual feeling and the personal conviction we owe each other, is still in existence. In accordance with Friedhelm Hengsbach (2012) this attitude could be called the 'virtue of solidarity'. What, however, has undoubtedly got lost, is the control form cast in institutions. Here we are dealing with basic goods, with public or social goods.

During the last four decades, an extensive erosion of basic goods has happened, which means that former basic goods, respectively public goods such as health (and education), have been transferred into private responsibility and increasingly into the laws of the market. Public goods have turned into private goods. This does not only mean that the privatisation of former social state institutions have proliferated (and still do), but it also means that particular goods are subject to the laws of competition, which probably are only partly applicable to these goods.

Competition is directed towards products and services, but what about health and education products or patients and student customers who expect services? The formerly quoted sentence of Thomas Scanlon (1999), 'what we owe each other', refers to those areas in which human beings do not meet at eye level although they see each other as equals. The willingness, to see human beings as equals, although they are not meeting at eye level is called solidarity. The latter is a form of asymmetrical reciprocity in which, figuratively spoken, there is a side that gives and a receiving hand. Here, at least, the logic of giving dominates and not 'in general' the logic of competition and the logic of the market. Risks of life, which practically cannot be burdened on the individual's shoulders, are here mastered by the community.

This solidarity reaches beyond virtuous acting in unity. It is also this behaviour, the 'virtue of solidarity', that gets under severe pressure as soon as supporting institutions or control forms are reduced. Here the socio-economic, welldocumented cognition is valid so that justified action is dependent on just institutions. Without the institutional 'form of control' of solidarity, the virtue of solidarity erodes at any time. Moreover, in the environment of the debates about solidarity, the perspective of the strong ones who repeatedly refer to the too great strain of the giving ones and who understand the situation of the weak ones as the consequence of their own failure has prevailed:

The commonly felt basis of an elementary bond is faded out in the same way like the knowledge of experience that [particular] ... risks cannot be ascribed individually. That from the feeling and the cognition of unequal distribution of risks the insight of an asymmetrical mutuality follows, is willingly superseded. (Hengsbach 2012:189)

But perhaps medical ethics is not completely innocent of this development. To my mind, this has to do with the one-sided emphasis of the 'autonomy' in its discourses.

\section{Problems with the autonomy}

Patient autonomy has become very beloved and dear to us. For at least four decades it has been the centre of medical ethical debates and is evaluated as an important formula of emancipation. During the same time, however, the concept of patient autonomy has undergone a dynamics from which a problem has to be made.

The patient has become a mature and responsible person who has managed to liberate her- or himself - from case to case or both at a time, from the guardianship of a medical profession tending towards paternalism as well as from her or his passive role within society and politics. The two famous US-American moral philosophers in the field of medical ethics, Tom L. Beauchamp and James F.Childresss (1994) had distinguished between four ethical principles in their academic bestseller Principles of Biomedical Ethics, which are fundamental for the public health system: 'Respect for Autonomy', 'Nonmaleficence', 'Beneficence', and 'Justice'. The second and third principles have ever since been part of the moral canon of medical behaviour and acting. The fourth principle, 'Justice', could not come up with such a career. It remained, as they say, the wallflower of medical ethics and with it the idea of solidarity had become marginal for a long time. Questions of justice and solidarity, such as how to distribute resources fairly and how to limit medical interventions if necessary, had become second-rate. Why? Because the answers that had to be given were irksome.

\section{Autonomy: An indispensable right and ideal}

Probably we should distinguish between two things first: the patient and his or her autonomy. Thus, the first question is: What is a patient? According to the Latin origin a patient is a 'suffering human being'. He or she has not chosen his or her disease voluntarily and in the individual case it leads to a grave restriction of the active living conditions. For often, she or he is a sufferer, a quarreller, someone who has become passive in comparison with what she or he was able to do as a healthy person. Patients long for attention and depend on our care. For the duration of their disease or illness they have changed sides. It can undoubtedly be assumed as correct that turning towards them, having an open eye and talking to 
them, means an essential contribution to their recovery. We know that confidence can cure.

'What does autonomy mean?', sounds the second question. With regard to its subject, viz. the patient, one can point out two features: the autonomy of decision-making and the autonomy as a right. We speak about the autonomy of decision-making as soon as a patient has to agree to a plan of medical treatment. Such a decision is called an 'informed approval', as is known. The patient has been informed about and agreed to the course and the risks of a treatment. He or she has decided for him- or herself. The right on autonomy, however, means that persons have the possibility to claim this right to decide for themselves. Their determination on how to treat them medically cannot be evaded or neglected. Or, expressed in a more technical way, autonomy means the negative right, respectively the defensive right of the patient that action or operation by others must be omitted unless an approval has been given. The right on autonomy thus corresponds with the duty of omitting on the side of the treating authority. This autonomy of the patient is a normative principle which, to my mind, is indispensable. Its validity must never be called in question. A distinction, however, must be made between this principle or right and the definite and often limited abilities of a human being to practice autonomy. However, in which do the previously mentioned dynamics of a patient's autonomy exist?

\section{On the way to expecting too much}

This problem can best be understood by briefly reconstructing the changes of patient autonomy. Since the 1960s everyone has been talking about this phrase. Historically seen the Nuremberg Codex (1947) was its hour of birth. In case of medical experiment, so it says under point one of this codex, the voluntary and informed agreement of the patient or test person must be obtained. This right on autonomy, passed by the World Medical Association in 1964, was adopted into the Declaration of Helsinki. Only in modern medical ethics, as it came into existence in the USA at the beginning of the 1960s, that principle of agreement in the non-experimental medical practice was implemented. This kind of patient autonomy has been an ethical standard since and its validity is rightfully indisputable. Since the implementation of this 'informed agreement', the knowledge of patients, male or female, has become more and more enlarged. Autonomy here means self-determination: enlightenment and approval with the help of information.

The next step leads us to the responsible and mature patient. This type of patient knows his or her interests, is seen as a partner in the course of the treatment process and is capable of thinking about the means, the aim and the sense of a treatment. Here patient and doctor ought to communicate on eye level in the sense of 'Shared-Decision-Making'. The question, however, is in how far this model considers the unequal positions and the differentials of competence between the two sides. Autonomy here means maturity and responsibility through communication.
The third step leads us to the self-improving patient, whose level of demand has enormously changed. It is not the treatment of a disease or illness that becomes the focus of attention, but the improvement of health. This demands a strategy in which, increasingly, specific age restrictions are potentially seen as diseases, as in need and capable of improvement. Here autonomy means self-perfection through optimising intervention.

The fourth and last step is directly connected with the preceding one: now the patient is discovered as someone who participates in the market. He or she is to behave as a customer on the health market. Strategic and rational competence is required. Even as patients, the motives of the homo oeconomicus should not go astray. Health becomes a good which is worth competing for. Autonomy here means rationalisation through calculation.

This sketch deliberately accepts a certain simplification. The intimated development as a whole is in no way to be judged negative. But it is one-sided. In it the most important perspective is about to get lost. It is the one that sees the patient as a dependent, suffering human being who is in need of the care of others. And with him even solidarity threatens to disappear. The question of justice is forgotten. That is meant by a 'trap' of autonomy. This could lead to patients who expect too much from themselves and it could lead to their isolation. The autonomous patient would then be a lonely and neglected human being. Dealing with patients and also their self-image is characterised by a culture of liberty rights. At the same time the importance of selfdetermination in some situations is increasingly mixed up with the demand of wanting and being able to decide and longing for everything.

We are increasingly losing the sense for our finiteness and the necessary extend of solidarity. The one-sided orientation of vast parts of medical ethics on 'autonomy' has let the level of demand run riot. In not just a few patients or potential patients' minds it has developed into a license of wanting often to their own disadvantage.

The outlined development is part of an overall social drive and therefore cannot be examined in isolation. Meanwhile we have become citizens of a 'Project-Polis' (Luc Boltanski \& Éve Chiapello 2007) in which we increasingly understand ourselves as entrepreneurs of our own behalf. Our 'entrepreneurial ego' (Bröckling 2007) forces us to become flexible project-planners of our lives. Autonomy has then become an obligation, which does not call a halt to any spheres of life. At the latest we must now deal with the status of the good of health.

\section{The good of health: Three theses}

In the following I roughly try to cover these 'specific conditions of the good of health'. The focus will be on three aspects: Firstly the construction of the good 'health' has to be grasped. The answer is that this good is created by our interpretations. 
It depends on our interpretations and it is neither a matter of course nor a naturally given fact. But where are the limits of interpretation? Can we shift the limits just as we like? Therefore, in the second place, the range of interpretation has to be limited through a description of the phenomenon health. Thus, I support the thesis that we should understand health from the perspective of disease respectively to that of the patient if we do not want to run the risk of missing important points of view. Thirdly, as a factual consequence of the two mentioned reflections, the question has to be asked, viz. what status 'health' has in the system of goods. Hence, the question has to be answered whether 'health' is a private or a public good.

To start with, we must clarify what a good is. A good is a circumstance which we appreciate. This easy phrasing makes it instantly clear that an abundance of goods exist. This abundance corresponds with the presumably immense amount of things that human beings appreciate. A good is always important for me, which means for the particular person, and we are many. However, it is uncertain that what is important for $m e$, is also of real importance beyond $m y$ interests. Therefore, we must turn our intention to the various kinds of goods and particularly ask the question whether all goods are apt for the market. One can distinguish between four kinds of goods: the 'existential' the 'private', the 'public' and the 'common' goods.

Existential goods are ones that are of fundamental quality for the life of every human being and whose partial or total absence means an immediate restriction in a person's life. It is clear that health is such an existential good. Private goods are ones whose high esteem is optional to us. 'Optional' here has two meanings: their high esteem is up to us. We are free to strive after them or not and they do not have any consequence in form of an obligation for others. The choice between Mozart and Madonna is up to me. Whether classic or pop is a good for me, depends on my arbitrariness. The situation, however, is completely different with public goods.

In the Roman Law the category of the res extra commercium existed. It referred to things which could not pass into private possession and with which no trading was therefore allowed. The so-called extra commerciality was related to 'holy' objects (res divini iuris), 'public legitimate' objects (res publicae), and the res communes omnium, namely the common goods of all people (like for example air and water). The latter goods we would call 'common goods'. To these 'commons', the USAmerican Nobel Prize winner for economics, Elionor Ostrom (1990; 2012), dedicated her scientific life. The res publicae are called 'public goods' today.

The division of goods into existential, private, public and common goods is not independent from our decisions and our interpretations. These different categorical goods do not grow on trees neither are they of natural origin. It is us who decide with our interpretations what we subsume under these particular categories. If we want to do so politically, we could declare water as a private good, which is not extracommercial. It cannot be excluded that, in future, even air will achieve such a commercial status. What we traditionally understood as public goods - legal certainty, education, health, detention, public traffic and others - can be transformed into private goods if we want. Such goods are then put out of the general public's competence. In other words, they are privatised and their distribution happens according to the market trend.

Public goods are traditionally seized by means of two kinds of criteria of which at least one must be given: the 'nonrivalry' and the 'non-exclusiveness'.

Non-rivalry means that the consumption of these goods by one person does not disadvantage another one, so that rivalry cannot arise: $m y$ education contributes to the education of others and does not take away anything from their education. 'Non-exclusiveness' means that there is no point in excluding anyone from the consumption and thus the usage of goods. If we want to exclude certain persons from the good of legal certainty, we would literally neutralise this good, because legal certainty for a few people would finally mean legal uncertainty for all. But does this also apply to the good of health?

This largely depends on how we interpret 'health' respectively to 'disease' or 'illness'. Dependent on these interpretations, the criteria of their just distribution will be changed. Up for discussion is not whether we distribute the good health, but how we do it. About this question, the influential North American colleague, Michael Walzer (2002), writes:

So we are distributing lives of a certain sort, and what counts as justice in distribution depends on what that 'sort' is or, better, on the meaning of lives like that for the people whose lives they are. We also distribute life itself, mere life, physical life, which is given and taken in courts of law judging capital cases, or on the battlefield, or in hospitals. Here the criteria are entirely different; we make no inquiry into the talent of the professional qualifications of the defendant, the enemy soldier, or the patient. It is the guilt or innocence of the defendant, the threat posed by the enemy, and the illness of the patient that determine our response. (p. 24)

When we want to know how to distribute, we must have a close look at our interpretations of these goods. Do these interpretations possibly have limits? Can we interpret just as we like, and by what is our 'rage of understanding' (Hörisch 1998) put in its place? This brings us then to the second thesis.

Our interpretations find their limits with the phenomena, which brings us to the second part of our consideration. We should not interpret just as we like and be led by the phenomena. That means we should not adhere our interpretations against the phenomenon which we explain, unless we accept its false shape. In that case the interpretation would remain in a permanent confrontation with the phenomenon of the kind of appearance it claims to interpret. Regarding health and disease or illness it can 
be said, to my opinion, that their individualisation, which means the increasing ascription of responsibility for health and illness to the individual person and the declaration of the patient to a customer, is very much mistaken. Against the individualisation of illness or health, the risks of illness can only, in a lesser degree, be ascribed individually.

However, we must not take it too lightly. The public good of legal certainty results analytically from the meaning of the word: whoever privatises legal certainty, wipes it out. The legal certainty of a few would result in an immediate legal uncertainty of all. All this, however, is not valid in the case of health. We can state, without any self-contradiction, that human beings may be excluded from the treatment of a disease because of the lack of financial return. We can also state without contradiction that health performances have a competing character. Some say that nothing is to be objected against a competition for admission conditions to the achievements of the public health system. Now and then the sentence is heard that health is, just like the income, a result of labour and luck. Their unequal distribution is not more unjust than the differences in income, which in liberal societies are (indeed) unavoidable.

During the last 30 years there was indeed a tendency traceable that points into this direction. The enormous concentration on questions of health, which has spread, is a concomitant of a new assignment of competence and responsibility. It is the individual who is mainly responsible for his or her health. Supposing this statement is true, health would, without any question, be an existential and private good. This is, however, incorrect. The falseness of this opinion can be demonstrated on the basis of a rather simple phenomenology of health - a phenomenology that can hardly be dismissed.

By phenomenology we understand the following: Even if it is difficult to give a precise definition of health, which means to say what it is in detail, we know relatively well how health comes into existence. A number of factors can be named that determine health. The latter is also provided with a structure of conditions which we realize as soon as we try to see things without blinkers. This is exactly what we mean when we speak of phenomenology: It is the attempt to recognise facts without such blinkers. As soon as we apply such a way of looking at the phenomenon of health, it becomes obvious how one-sided or even tinged with ideology our view on health is - our opinions of the how of health.

Firstly, people owe their health to the care of others. Long before we are able to take care of ourselves, others have already done so. In this sense health has literally been donated to us. We owe it to a network of protagonists who have taken us on the way of a healthy life or have at least seriously tried to achieve this aim. And for our whole lifetime our health remains embedded in such a network. Without others we would be ill or most probably not even alive.

Secondly, our genetic constitution or bio-psychological coding, which determines our condition to a high degree, even though not exclusively, has not been chosen by ourselves. Although the amount or intensity of the determining power of the genetic program is quite contentious (and probably will be in future), it is difficult to deny that people on the basis of their different and farreaching non-corrective genetic pre-information will lead a particularly different healthy or diseased life.

Thirdly, accidents, misery, misfortune and strokes of fate, which altogether endanger our health permanently and even can ruin it, belong on the whole to the passive of our lives. Whether we are or remain healthy, depends on a bundle of incidents which we have to go through. They are not at our disposal and we can neither control nor determine them.

Fourthly, we have not chosen our place of birth. We have been born into a culture, the practice and convictions of which are of severe influence on our health. That life can be extremely unjust - this obvious (and true) sentence refers to the signature of our cultural origin and background. The cultural development of our life forms the quality of our physical and spiritual or emotional health in a decisive way. To free us from this influence is extremely difficult.

Fifthly, as already mentioned, we have not chosen our place of birth. The environment conditions we are exposed to are only to a lesser extend subject to the influence of the individual. The individual can hardly turn the environment conditions into positive ones for himself. The ecological structure of the circumstances of our lives, however, has enormous power over our state of health. From the perspective of our own exercise of influence on these circumstances we must state that we are much more engraved than engraving.

Sixthly, the social conditions in which we (must) lead our lives determine our expectation of life. Here, indeed, the iron law exists that the position, which we occupy on the ladder of social hierarchy, is decisive for the duration of our lives. Here a circular structure of conditions can be assumed. The unjust social conditions lead to an inequality in the field of health which, in its turn, results in social inequality. Moreover, patterns concerning the risks of health are often genetically left among the generations. Mobility on the mentioned ladder naturally exists, but it underlies 'on balance' multifarious restrictions. That ladder meanwhile seems permeable rather downwards than upwards.

Seventhly, the working conditions under which we spend considerable parts of our lives, can be conductive to our health. They often modify our health in a negative way. Stress, rush and increasing acceleration, exorbitant efficiency demands (induced by ourselves or by others), the constraint to be successful, flexibility, and permanent willingness of reform do cut deep into our health. This distribution of risks turns out to be most varying, but the mentioned characteristics of our present professional existence seem to spread over all kinds of jobs inexorably. The greatest health risk, however, is the uneasy working conditions and unemployment. Social stress 
and gratification risks are, as far as health is concerned, enormously precarious.

Eighthly, the level of education, which we have, moulds our health extremely strong. Information that strengthen our health competence and a way of life that contributes to our health, depend on education and thus are distributed very differently. Provision, the attention of rules of thumb and the avoidance of unnecessary risks - they all lie in our hands presumed that we have the necessary knowledge and are motivated to act accordingly.

Ninthly, the quality of the according health system - the standards of the medical profession, the attainability and the social availability of the achievements adduced there, the functioning of bureaucracy, the human circumspection, and the restraint of the resources - all this is of decisive influence on the possibility of leading a healthy life. However, the contribution of the health system to the health of the population is often overestimated.

The nine mentioned conditions are obviously interdependent and are connected with each other to a considerable extent. They point out to the conditioned character of our health. As healthy and ill persons we are in a complex system of conditions and thus exposed to dependencies. We can (and should) of course contribute to leading a healthy life, but this asset proves to be rather trifling. Recalling that health is an existential good, it becomes instantly clear how negligible our access to the quality of this existential good finally is. Because it is of existential character, it belongs to the conditional goods, which means to the conditions of our existence's possibility. It becomes obvious, however, that the conditional good of health is in many ways a conditioned one. Particularly, with regard to the important existential good of health, we are exceedingly dependent - dependent on others. The consequence of this is that the others - and also most of us being able to care for others - are responsible. Our existence lies vastly in the hands of others.

From all these considerations only one thing follows after all: We have our health only for a small part in our own hands. Although it is difficult to present a precise numbering of the individual contribution - estimates hardly reach beyond $15 \%$ - it becomes clear against the background of the just outlined structure of conditions that the popular statement, viz. human beings were health agents on their own behalf, is nothing but a crude ideology. So, politically only one conclusion is possible: Health is a matter of justice. It needs compensation and measures of balance to avoid that health remains distributed unjustly. This political task can hardly be accomplished by the health system, not even by health politics (in a narrow sense). Here the social structure of our society is put forward for discussion. But the institutions of the health system as well as the health political measures contribute to easing this problem of justice.

Health is obviously, on the basis of its manifold conditions, a public good. Therewith the third question has been also answered. The transformation of health into a private good is obviously the consequence of a severe misunderstanding, a disregard of the conditions under which health and disease or illness exist and under which health can be preserved and illness be cured, eased or, at least, suffered.

Today we need a broadening of our perspective. It is really a topic of severe normative questions - questions of how we comprehend health politics and in what way we want, can, and should realize the concept of the health system. We must not identify all this with the limited perspective of medical ethics or the 'just health care'. It is more than this. It is not only a question of ethics of the health system, but it is a matter of 'just health'.

Also, in matters of health and the system of health we should 'neither hurt the ideal of equal consideration nor that of individual responsibility' as Ronald Dworkin (2012) formulates it. But it does not make sense to privatise risks of disease or illness completely. Who does so, hurts the principle of equal consideration and finally causes decisive harm to the liberty of the individual.

With regard to health and illness, no justice, no approximate equality exists without our social and institutional interventions. We are in every respect dependent on the asymmetric care of others and are, for our part, submitted to the obligation of returning in solidarity the care we receive or which is promised by others in case of need. People who see patients as customers who buy on the market of the health system, compete with others, mobilise their purchasing power and act as homines oeconomici, forgets the conditional character of health as a good. In addition they forget the simple fact that ill human beings are suffering human beings. These human beings are dependent on an attitude of giving and therefore an economy of health is always additionally an economy of contribution and donation.

Historically seen the welfare state was the 'guarantor of the production of those goods which are not apt for the market' (Schaal \& Ritzi 2012:7). It protects the continued existence of public goods against infringements that subdue them completely to the competition and the economic demands on efficiency. I say with deliberation 'completely', because nobody can deny in all seriousness that market. Competition and efficiency also play an important role in the health system. In this sphere the easiest general rule for the time being could be: 'Where no competition is possible, the community is responsible.' Neo-liberalism, however, has set the points in a decisively different way. One of its central ideas - the idea of an achievement-oriented definition of social justice - has pressed the idea of an inclusion-oriented understanding of social justice which means to put those who are not efficient under the protection of the social community. However, a health system, oriented at the ill human being, can finally not apply to an efficiency-oriented idea of justice. This would, in its core, be contradicted with its purpose. For this reason health remains one of the very important and essential public goods. It would be good if we, 
in future put a restriction on the naming of a patient as customer. Hereafter we can continue reflecting upon what efficiency, profitability and rationalisation can mean in the health system.

\section{Acknowledgements}

Competing interests

The author declares that he has no financial or personal relationships which may have inappropriately influenced them in writing this article.

\section{References}

Beauchamp, T.L. \& Childress, J.F., 1994, Principles of Biomedical Ethics, 4th edn, Oxford University Press, Oxford.
Bröckling, U., 2007, Das unternehmerische Selbst: Soziologie einer Subjektivierungsform, Suhrkamp, Frankfurt a. Main

Dworkin, R., 2012, Gerechtigkeit für Igel, Suhrkamp, Berlin.

Hengsbach, F., 2012, Die Zeit gehört uns: Widerstand gegen das Regime der Beschleunigung, Westend, Frankfurt a. Main.

Hörisch, J., 1998, Die Wut des Verstehens, Suhrkamp, Frankfurt a. Main.

Ostrom, E., 1999, Die Verfassung der Allmende: Jenseits von Staat und Markt Mohr-Siebeck, Tübingen.

Ostrom, E., 2012, Was mehr wird, wenn wir teilen; Vom gesellschaftlichen Wert der Gemeingüter, Oekom, München

Scanlon, S., 1999, What we owe to each other, Harvard University Press, London.

Schaal, G.S. \& Ritzi, C., 2012, 'Neoliberalismus und Postdemokratie: Bausteine einer kritischen Gesellschaftstheorie', Ethik und Gesellschaft (e+g) 2, 1-26.

Stuckler, D. \& Basu, S., 2013, The Body Economic. Why Austerity Kills, Basic Books, New York.

Walzer, M., 1983, Spheres of Justice: A defence of Pluralism and Equality, Basic Books, New York.

Walzer, M., 2002, Thick and Thin. Moral Argument at Home and Abroad, Notre Dame Press, Notre Dame. 